\title{
Strength Training to Enhance Early Recovery after Hematopoietic Stem Cell Transplantation
}

\author{
Eileen Danaher Hacker ${ }^{1, *}$, Eileen Collins ${ }^{1}$, Chang Park ${ }^{1}$, Tara Peters ${ }^{1}$, Pritesh Patel ${ }^{2}$, \\ Damiano Rondelli ${ }^{2}$ \\ ${ }^{1}$ College of Nursing, University of Illinois at Chicago, Chicago, Illinois \\ ${ }^{2}$ College of Medicine, University of Illinois at Chicago, Chicago, Illinois
}

Article history:

Received 24 October 2016

Accepted 23 December 2016

\section{Key Words:}

Exercise

Fatigue

Physical activity

Functional ability

Stem cell transplantation

Strength training

\begin{abstract}
A B S T R A C T
Intensive cancer treatment followed by hematopoietic stem cell transplantation (HCT) results in moderate to severe fatigue and physical inactivity, leading to diminished functional ability. The purpose of this study was to determine the efficacy of an exercise intervention, strength training to enhance early recovery (STEER), on physical activity, fatigue, muscle strength, functional ability, and quality of life after HCT. This singleblind, randomized clinical trial compared strength training $(\mathrm{n}=33)$ to usual care plus attention control with health education (UC + AC with HE) $(n=34)$. Subjects were stratified by type of transplantation and age. STEER consisted of a comprehensive program of progressive resistance introduced during hospitalization and continued for 6 weeks after hospital discharge. Fatigue, physical activity, muscle strength, functional ability, and quality of life were assessed before HCT hospital admission and after intervention completion. Data were analyzed using split-plot analysis of variance. Significant time $\times$ group interactions effects were noted for fatigue $(P=.04)$. The STEER group reported improvement in fatigue from baseline to after intervention whereas the $\mathrm{UC}+\mathrm{AC}$ with HE group reported worsened fatigue from baseline to after intervention. Time $(P<.001)$ and group effects $(P=.05)$ were observed for physical activity. Physical activity declined from baseline to 6 weeks after hospitalization. The STEER group was more physically active. Functional ability tests (timed stair climb and timed up and go) resulted in a significant interaction effect $(P=.03$ and $P=.05$, respectively). Subjects in the UC + AC with HE group were significantly slower on both tests baseline to after intervention, whereas the STEER group's time remained stable. The STEER group completed both tests faster than the UC + AC with HE group after intervention. Study findings support the use of STEER after intensive cancer treatment and HCT. Strength training demonstrated positive effects on fatigue, physical activity, muscle strength, and functional ability. The exact recovery patterns between groups and over time varied; the STEER group either improved or maintained their status from baseline to after intervention (6 weeks after hospital discharge) whereas the health education group generally declined over time or did not change.
\end{abstract}

(C) 2017 American Society for Blood and Marrow Transplantation.

\section{INTRODUCTION}

Intensive cancer treatment followed by hematopoietic stem cell transplantation (HCT) is considered curative for a number of hematological malignancies [1] but it is associated with high 100-day treatment-related mortality [1] and devastating complications [2,3]. These complications result in highly distressing symptoms, significantly impaired functional status, and diminished quality of life (QOL) that can last for years after treatment [4-7]. A marked reduction in physical activity after intensive cancer treatment and HCT has been

\footnotetext{
Financial disclosure: See Acknowledgments on page 667

* Correspondence and reprint requests: Eileen Danaher Hacker, PhD, Department of Biobehavioral Health Science, University of Illinois at Chicago, 845 S. Damen Avenue, (M/C 802), Room 760, Chicago, IL 60612.

E-mail address: ehacker@uic.edu (E.D. Hacker).
}

documented [8]. Up to $90 \%$ of HCT recipients report severe persistent fatigue [9-12]. Although the relationship between physical activity and fatigue is not completely understood, sustained physical inactivity after HCT is sufficient to cause loss of muscle mass with resulting decreases in strength. Muscle mass losses during the first 6 months after HCT are frequently not regained even 5 years after transplantation [13-15].

This clinical picture of impaired recovery after intensive cancer treatment and HCT closely resembles the clinical syndrome of frailty in older adults. Using Fried's Clinical Phenotype of Frailty in Older Adults [16] as a guide and adapted for HCT, we hypothesized that muscle strength plays a crucial role in preventing the development of physical deconditioning/frailty and eventual progression to disability in HCT recipients (Figure 1). The working hypothesis is that 


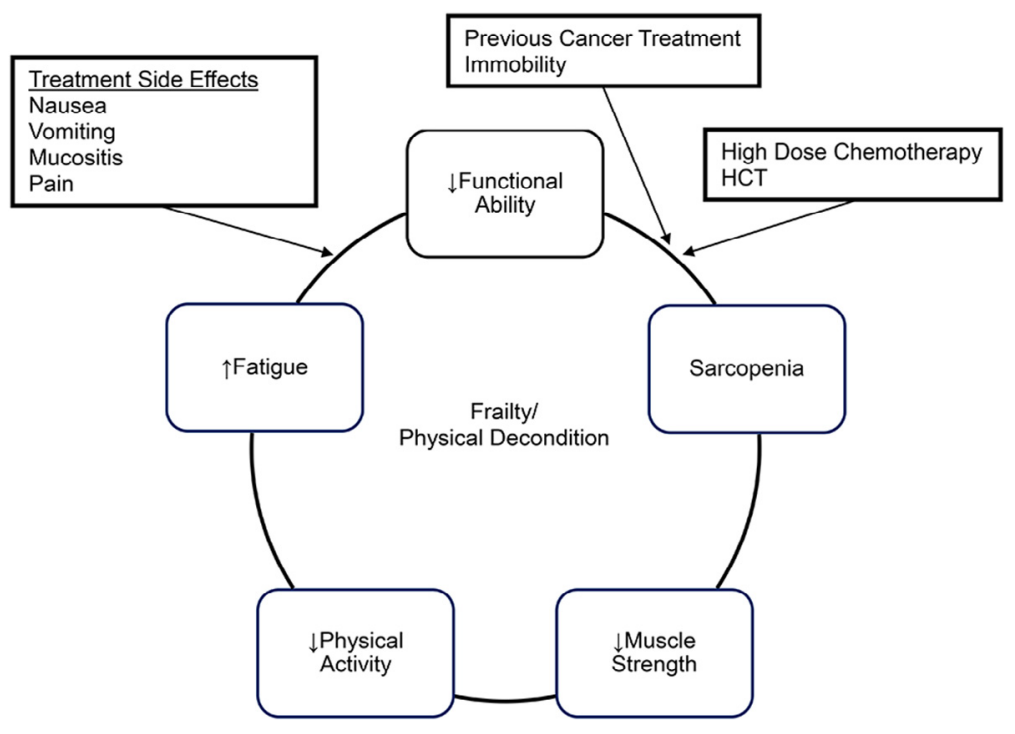

Figure 1. Model of frailty/physical decondition (adapted from Fried's Clinical Phenotype of Frailty in Older Adults, 2001).

muscle strength is needed to break the negative cycle of physical deconditioning/frailty that begins with loss of muscle mass leading to decreased strength $\rightarrow$ reduced physical activity $\rightarrow$ fatigue $\rightarrow$ decreased functional ability $\rightarrow$ even further loss of muscle mass. Without intervention, frailty and long-term disability ensue even though the HCT survivors are free of cancer [17]. Thus, there is a tremendous need to break this negative cycle and develop effective interventions to reduce loss of muscle mass and enhance early recovery.

This study focuses on strength training to enhance early recovery (STEER) after intensive cancer treatment and HCT. Exercise is widely promoted as a means for improving physical functioning in people with cancer $[18,19]$. Strength training, in comparison to all other exercise modalities, most effectively builds muscle mass [20]; however, few studies have evaluated strength training in the HCT population. Most HCT studies combined strength training with aerobic exercises [21-27], making it difficult to disentangle the individual effects of strength training. Only 1 small HCT study, besides our pilot work, employed single-modality strength training [28]. Although beneficial effects were demonstrated, fatigue, physical activity, and functional ability were not assessed. Our pilot studies demonstrated that (1) strength training using elastic resistance bands has potential positive effects on physical activity, fatigue, and QOL; and, (2) strength training is feasible during the early recovery period if the intervention is tailored to the individual's capabilities, making subject burden reasonable $[29,30]$.

A strength training intervention to block or reverse physical deconditioning after HCT is vitally important for maintaining physical independence, as demonstrated by the ability to perform everyday activities. From a cost and subject burden perspective, it is imperative that the independent effects of strength training be established in this challenging population. Furthermore, strength training after HCT may be more important than aerobic exercise, according to the American College of Sports Medicine [31]. Given the importance of maintaining muscle mass and reducing the debilitating effects of intensive cancer treatment and HCT, there is a clear need for a randomized clinical trial (RCT) to evaluate a strength training intervention in the early recovery period after HCT. The purpose of this single-blind RCT was to compare STEER to usual care plus attention control with health education (UC $+\mathrm{AC}$ with $\mathrm{HE}$ ) after intensive cancer treatment and HCT on physical activity, fatigue, muscle strength, functional ability, and QOL. This study addresses the following question, "Does strength training enhance recovery from baseline to 6 weeks after hospital discharge after HCT?"

\section{METHODS}

Design

This study employed a single-blind RCT to test the efficacy of the STEER invention compared with UC + AC with HE after HCT. Subjects were stratified by type of transplantation (allogeneic or autologous) and by age ( $\leq 60$ years of age or $>60$ years of age). Random allocation to treatment and allocation concealment were achieved using sequentially numbered, opaque, sealed envelopes [32].

STEER consisted of a comprehensive program of progressive resistance using elastic resistance bands to strengthen the upper body, lower body, and abdominal muscles. UC + AC with $\mathrm{HE}$ consisted of a standardized health education program. Both study arms contained an in-hospital component followed by a 6 -week post-hospital discharge phase (described in detail below). Dependent variables included physical activity, fatigue, muscle strength, functional ability, and QOL. Variables were measured before admission to the hospital for the HCT to provide baseline information and during the seventh week after hospital discharge to provide information regarding the efficacy of the intervention and recovery after HCT. The study was approved by the institutional review board.

\section{Sample and Setting}

Consecutively eligible patients 18 years of age or older scheduled to undergo HCT at a Midwestern academic medical center were invited to participate. Patients who were initially eligible for inclusion were scheduled to undergo HCT for an underlying malignancy and cognitively able to understand the purpose of the research. Patients contemplating HCT undergo an extensive medical work-up before transplantation. All of the pretesting procedures are standard of care and were not considered part of the research. The medical work-up generally includes a history and physical; multigated acquisition scans to assess heart function; spirometry to assess pulmonary function; various blood tests to assess kidney, liver, and blood cell function and exposure to viruses; chest x-rays; urinalysis; and a dental exam. The treating physicians reviewed all the pretests and provided approval for subjects to participate in this study. Subjects were excluded if they presented with a significant comorbidity, such as impending pathological fracture, that would be make it potentially unsafe to exercise if randomized to STEER. To continue to participate in the study after hospital discharge, subjects were required to be ambulatory.

Enrollment was open from May 2013 through August 2015. One hundred eighteen people scheduled for HCT were eligible to participate. Eightyfour (71\%) agreed to participate. Multiple reasons for declining to participate 
were provided, including too much on their plate and not interested in participating in the study. Five of the 84 subjects who agreed to participate were withdrawn from the study before completion of any research activities. An additional 4 subjects were withdrawn from the study after completing baseline testing. These 9 subjects did not proceed to HCT. Seventy-five subjects were randomized (STEER group, $\mathrm{n}=37$; $\mathrm{UC}+\mathrm{AC}$ with HE group, $\mathrm{n}=38$ ). Seven subjects expired before the end of the study and 1 was lost to follow-up (STEER group, $\mathrm{n}=4$; and $\mathrm{UC}+\mathrm{AC}$ with HE group, $\mathrm{n}=4$ ). Sixty-seven subjects completed the study; thus, the study retained $89 \%$ of the subjects who initially enrolled and received a transplant. The primary reason for subject attrition was death and the death was attributable to the underlying medical condition.

\section{Strength Training Intervention}

The strength training intervention, STEER, consisted of a comprehensive program of progressive resistance to strengthen the upper body, lower body, and abdominal muscles using elastic resistance bands (Therabands, Hygenic Corp., Akron, $\mathrm{OH}$ ) and body weight for resistance. Subjects received instruction and began active range of motion 2 times per week while hospitalized for HCT. Moderate-intensity strength training began immediately after discharge from the hospital. Hospital discharge was chosen as the time to initiate the moderate intensity training as HCT patients are generally considered medically stable; thus, it is a common safe point to initiate the intervention. Training continued 3 times per week for 6 weeks after hospital discharge. The Borg rating of perceived exertion scale, a 20-point scale, was used to estimate the intensity of the resistance [33]. The moderateintensity strength training prescription was based on a rating of somewhat hard (Borg scale, 13). Instruction and training were conducted by the principal investigator or a trained member of the research team.

STEER consisted of 11 preselected exercises with concentric and eccentric muscle contractions as follows: (1) 8 exercises using elastic resistance bands (chest fly, biceps curl, triceps extension, shoulder shrug, shoulder upright row, shoulder lateral raise, knee flexion, and knee extension) and (2) 3 exercises that used body weight as resistance (wall push-ups, squats, and bed sit-ups). Some subjects were not able to perform all 11 exercises when the moderate-intensity strength training intervention was initiated after hospital discharge. As a result, the initial moderate-intensity exercise prescription required tailoring to the individual's capabilities. Subjects were prescribed as many exercises as they could perform, starting with the easiest exercises and advancing to the most difficult. Subjects provided return demonstrations of the exercises to ensure proper form and reduce the chance of injury. All subjects rated their strength training program as moderately hard, regardless of the number of exercises performed, resistance band used, and/or number of repetitions/sets performed.

The STEER intervention employed a supervised/unsupervised approach. Subjects were seen once or twice each week during their regularly scheduled clinic visit to exercise under the supervision of a member of the research team. These 1-on-1 sessions were conducted in clinic exam rooms. Changes to the exercise prescription, mostly advancements, were made at that time, facilitating progression with the exercise prescription. Progression of the exercise prescription was structured to first increase the number of repetitions, followed by increasing the number of sets from 1 to 2 sets, and finally increasing the resistance level of elastic bands. Subjects were encouraged to exercise on their own 2 more times during the week for a total of 3 times per week. Subjects documented completion of each individual exercise, including information about the number of repetitions and sets, on preprinted exercise logs. Subjects were queried regarding exercise adherence and tolerance to the exercise prescription during weekly clinic visits.

This clinic/home-based strength training program was chosen for multiple reasons: (1) reduces the risk of exposure to pathogens that may be acquired in other public places such as gyms; (2) reduces the burden of traveling to and from a gym or laboratory in patients who may be experiencing significant fatigue; (3) elastic resistance bands are portable and can be easily used in a clinic or home setting; (4) makes effective use of the time patients spend waiting in clinic to exercise under supervision; and (5) the equipment is affordable so the training program can easily be implemented on a larger scale if successful. Studies involving elastic resistance exercises demonstrate increased strength [34-37], improved function and decreased disability $[38,39]$, and improved range of motion and flexibility [40]. Elastic resistance exercises have been used in a variety of populations, including multiple myeloma patients [22], the elderly [34,35], cardiac patients [41], and in our own pilot studies with HCT patients [29,30].

\section{UC + AC with HE}

The UC + AC with HE intervention was implemented in 2 phases, similar to the STEER intervention. During hospitalization for HCT, subjects in the $\mathrm{UC}+\mathrm{AC}$ with HE group received 2 visits per week, during which they were given the opportunity to discuss the hospital experience. After hospital discharge, the 6-week health education program was implemented. The UC + AC with HE subjects were seen once each week in clinic during scheduled clinic appointments to deliver the standardized 1-on-1 education intervention. The intervention was delivered in the clinic exam rooms. Topics included protecting your health, working with your doctors, dealing with finances, and guides for recommended tests and procedures after HCT. Publicly available patient education materials from the Center for International Blood and Marrow Transplant Research and National Marrow Donor Program were used. Subjects received usual care recommendations regarding rest, physical activity, and exercise from their attending HCT physician. Subjects were not told that they could not exercise.

\section{Instrumentation}

Physical activity

Physical activity was objectively measured during waking hours using a wrist-worn accelerometer (primary aim), the Actical (Philips Respironics, Bend, OR) and through self-report (Godin leisure-time exercise questionnaire) [42]. The objectively measured physical activity data were analyzed using the Actical software (Version 3.0). The following criteria were met for inclusion in the data analysis: (1) at least 10 hours per day of physical activity data was provided during waking hours; and, (2) a minimum of 3 days of data were provided for both data collection periods (baseline and after intervention). The average physical count per minute is reported.

Accelerometry is a well-established method to assess physical activity. Intra- and interinstrument reliability were established using a shaker table under 6 different conditions of various intensity to produce a range of accelerometry counts [43]. Correlations with the maximal 6-minute walk $(r=.74, P<.001)$, level of obstructive disease (forced expiratory volume in first second percent predicted, $r=.62, P<.001$ ), and dyspnea (Functional Status and Dyspnea Questionnaire, dyspnea over the past 30 days, $r=-.29 ; P<.05$ ) provide support for concurrent validity in people with chronic illnesses [44]. Successful use of wrist actigraphy to quantify physical activity has been reported in several recent studies involving people with cancer, including HCT patients [8,45-47].

The Godin leisure-time exercise questionnaire was used to assess selfreported physical activity in terms of usual leisure time exercise behaviors [42]. This brief, self-report, 4-item instrument assesses the frequency of periods of strenuous, moderate, and light activities greater than 15 minutes in duration during a typical 7-day period. The instrument was modified to include questions regarding average duration [48]. The instrument has established test-retest reliability [42]. Large correlations between the accelerometers and the Godin leisure-time exercise questionnaire provide support for convergent validity [49,50].

\section{Fatigue}

Fatigue was measured with the Chalder fatigue scale [51] and fatigue subscale of the European Organization for Research and Treatment of Cancer Quality of Life Questionnaire (EORTC QLQ-C30) (described below) [52]. The Chalder fatigue scale is a multidimensional, self-report instrument that measures physical and mental fatigue using a 4-point Likert scale. Higher scores indicate greater fatigue. The 11-item instrument has excellent psychometric properties and has been successfully used in hospitalized and communitydwelling subjects, including those with hematological malignancies [53,54]. Normative mean scores for the overall fatigue score have been reported as 12.2

$(\mathrm{SD}=4.0)$ in the general Norwegian population [55]. The fatigue subscale of the EORTC QLQ C-30 (3 items) measures physical fatigue using a 4-point Likert scale. The EORTC QLQ C-30 is described in detail below. The fatigue subscale has been used extensively in people with cancer and has established reliability and validity [56].

\section{Muscle strength}

Three tests of muscle mass and strength were performed: ultrasonic measurement of the cross-sectional area of the rectus femoris, hand grip strength, and arm curl test.

Rectus femoris cross-sectional area. The rectus femoris cross-sectional area was measured using the SonoSite M-Turbo ultrasound system (FUJIFILM SonoSite, Inc., Bothell, WA). To assess rectus femoris cross-sectional area, subjects were positioned using a standardized procedure (supine with arms resting comfortably at their sides, pillow behind head, head of bed elevated to $20^{\circ}$, and legs relaxed with knees extended) [57]. The distance between the anterior superior iliac spine and the upper pole of the patella was measured in centimeters. Using the superior iliac spine as the starting reference point, the skin was marked with a pen at $75 \%$ of this distance on the dominant leg [58]. This ink line served as a visual aid for the point of ultrasound measurement. Placing the transducer perpendicular to the skin along the longitudinal aspect of the thigh at the $75 \%$ mark, the rectus femoris was located. This location was chosen as the most proximal position on the thigh where the rectus femoris would be visualized in all subjects using the 
linear transducer [59]. Subjects were asked to tense the muscle so that the rectus femoris was clearly identified and then relax the muscle completely. With the rectus femoris relaxed, 6 consecutive 2-dimensional images were taken. The cross-sectional area of the rectus femoris was obtained through manual tracing of the muscle borders using the SonoSite M-Turbo software.

As a proxy measure for muscle strength, ultrasound measurement of the rectus femoris has been significantly correlated with isometric maximum voluntary contraction in healthy subjects $(r=.80, P<.001)$ and people with chronic obstructive pulmonary disease $(r=.78, p<.001)$ [60]. Ultrasound measurement of the quadriceps has been used to successfully document significant declines in rectus femoris muscle mass after 1 week of leg immobilization in people with knee injuries $(P<.001)$, followed by significant increases in muscle mass after rehabilitation $(P<.01)$ [61]. Ultrasound measures are strongly correlated with the gold standard magnetic resonance imaging rectus femoris cross-sectional area $($ rho $=.88)[62]$.

Hand grip strength. Hand grip strength was measured using a Jamar dynamometer (TEC, Clifton, NJ). Testing was performed with subjects sitting with the shoulder adducted and neutrally rotated. The elbow was flexed at $90^{\circ}$ with the forearm in a neutral position and the wrist between $0^{\circ}$ and $30^{\circ}$ with $0^{\circ}$ and $15^{\circ}$ ulnar deviation, according to recommendations [63]. The results are reported as the mean of the 3 trials for the dominant hand [64]. Reported test-retest reliability coefficients for hand grip strength were .91 for men and .94 for women [65]. Hand grip strength was validated as an indicator of upper extremity strength by strong correlations between hand grip strength and forearm muscle area $(r=.73)$, upper arm muscle area $(r=.71)$, and total muscle mass $(r=.65)$ [66-68].

Arm curl test. Upper body strength was measured with the 30-second arm curl test. Subjects were instructed to complete as many arm curls as possible in 30 seconds using the dominant arm. Men used an 8-pound weight and females used a 5-pound weight. The arm curl test has been used as part of the Senior Fitness Test $[69,70]$. The 30 -second arm curl test has a moderately strong correlation with the chest press and is a valid surrogate for upper body strength in frail individuals [71].

Functional ability

Four objective functional ability tests were performed: timed stair climb, the timed up and go test, 15-foot walk time, and 30-second chair-stand test.

Timed stair climb. The timed stair climb was used as an indicator of lower body strength [72]. Subjects were timed with a digital stopwatch as they ascended a flight of 9 steps. Results are reported in seconds to reach the top of the flight of stairs. The timed stair climb has excellent test-retest reliability $(r=.94)$ [73]. The results for timed stair climbs have been significantly correlated with isokinetic strength measurement of knee flexors and extensors [74].

Timed up and go test. The timed up and go test was used as a measure of basic functional mobility [75]. The timed assessment begins with individuals sitting down in a standard chair, rising, walking 8 feet, turning around and returning, then sitting down again. The test demonstrates strong reliability with intraclass correlations ranging from .93 in healthy adults [76] to .96 in community dwelling elders [77]. The test discriminates between those with worse home independence and increased risk for falls providing support for construct validity [77,78]. The test has been used successfully in people with cancer [79].

Fifteen-foot walk time. The 15-foot walk time test (4.57 meters) was used as an indicator of gait speed. Gait speed was determined by the number of seconds it took to walk 15 feet [80]. Subjects started in a standing position and were instructed to walk as quickly and safely as possible pass the 15 foot line, marked clearly with tape. Timing started when the foot first passed the start line and ended when both feet passed the 15-foot line. Subjects were told that they should only slow down after passing the line. Subjects were allowed to use assistive devices, such as canes. Four-meter gait speed has excellent reliability and validity in older adults [81] and those with chronic obstructive pulmonary disease [82]. The 4-meter gait speed is highly correlated with incremental shuttle walk and the 10 -meter walk test, providing support for concurrent validity.

Thirty-second chair-stand test. The 30-second chair-stand test was conducted as an indicator of lower body strength. The 30-second chair-stand test involves recording the number of stands (sitting in a chair to standing erect) that a subject can complete in 30 seconds. Good stability and reliability have been reported in community-residing older adults, with testretest correlations of .84 for men, .92 for women, and no significant changes in scores over a 2 -day period [83]. The 30 -second chair-stand test was validated as an indicator of lower body strength with moderate correlations between the chair-stand test and the 1-repetition maximum weightadjusted leg-press performance ( $r=.78$ men and .71 women). Chair-stand performance was able to discriminate between lower-active participants and higher-active participants $(P<.0001)$, providing support for construct validity through contrasted groups. The 30 -second chair-stand test is included in the Senior Fitness Test $[69,70]$.

\section{QOL}

The EORTC QLQ C-30 was used to measure QOL [52]. The EORTC QLQC30 (version 3.0) is a 30-item tool consisting of (1) 5 functional scales (physical, role, emotional, cognitive, and social); (2) a global QOL/health status scale; (3) 3 multi-item symptom scales (fatigue, pain, and nausea and vomiting); and (4) a number of single-item questions (dyspnea, appetite loss, sleep disturbance, constipation, diarrhea, and financial impact) [56]. Twentyeight items use a 4-point Likert scale. The global QOL/health status scale employs a 7-point Likert scale, with 1 being very poor and 7 being excellent. Items on the multi-item subscales are averaged and then converted to a 0 -to-100 scale. Higher scores on the 5 functional scales and the global QOL/ health status scale represent higher levels of functioning. Higher scores on the symptom scales and the single-item questions indicate higher degrees of symptomatology. The EORTC QLQ-C30 is a well-established and psychometrically sound instrument used worldwide in clinical trials involving people with cancer [56]. High internal consistency has been reported for all of the multi-item subscales, including the global QOL subscale (range, .80 to .94 ) $[52,84,85]$.

\section{Data Collection Schedule and Procedures}

Before hospitalization for HCT (baseline)

Wrist actigraphs were placed on the patient's nondominant hand to measure physical activity. The subjects were instructed to leave the device in place for the next 5 days. Subjects were instructed to carry on with normal activities, including bathing and showering, as the Actical is water-resistant. At the end of the 5-day period, subjects completed the 3 muscle strength tests, 4 functional ability tests, and the self-report questionnaires. The questionnaires were administered via interview. The muscle strength and functional ability tests took approximately 30 minutes to complete and the questionnaires took approximately 15 minutes.

\section{After Intervention (during the seventh week after hospital discharge)}

The procedures for data collection after intervention were the same as described for baseline.

\section{Data Analysis}

All data analyses were performed using SPSS (Version 22, IBM Corp., Chicago, IL). Descriptive statistics were calculated for all measures. Internal consistency estimates (Cronbach's alpha) were assessed for all multiitem Likert items (EORTC QLQ-C30). Split plot analysis of variance $(2 \times 2)$ was used to examine the effects of (1) group assignment (STEER compared to UC + AC with $\mathrm{HE}$ ); (2) time (baseline [before HCT] and after intervention, during the seventh week after hospital discharge to coincide with completion of the intervention); and ( 3 ) the group $\times$ time interaction on physical activity, fatigue, muscle strength, functional ability and QOL. The expected data trends were as follows: (1) both groups (STEER and the UC + AC with HE) would be similar at baseline; (2) the 2 groups would be significantly different after intervention; (3) the STEER group would improve over time or remain stable; and, (4) the UC + AC with HE would decline over time or not change.

\section{RESULTS}

\section{Demographic and Clinical Characteristics}

Table 1 displays the demographic and clinical treatment information. The data presented represent the 67 study participants who were randomly assigned to a group, underwent $\mathrm{HCT}$, and completed baseline and postintervention testing. Subjects ranged in age from 19 to 73 (mean, 53.3; SD, 12.2). The sample was racially diverse, composed of African Americans ( $n=26,39 \%)$; Caucasians $(n=30,45 \%)$; and Latino, Hispanic, or Mexican American ( $\mathrm{n}=10 ; 15 \%)$. More males $(n=41 ; 61 \%)$ enrolled than females $(n=26 ; 39 \%)$. The majority were married $(n=30 ; 45 \%)$ and completed some college as their highest level of education $(n=27 ; 40 \%)$. Over $40 \%$ reported incomes less than $\$ 30,000$ annually. All subjects received $\mathrm{HCT}$ for treatment of an underlying malignancy. Thirty-nine subjects (58\%) received an autologous transplant 
Table 1

Demographic and Clinical Characteristics $(n=67)$

\begin{tabular}{|c|c|c|c|}
\hline \multirow[t]{2}{*}{ Characteristics } & \multicolumn{3}{|l|}{ Value } \\
\hline & $\begin{array}{l}\text { STEER } \\
(\mathrm{n}=33)\end{array}$ & $\begin{array}{l}\mathrm{UC}+\mathrm{AC} \\
\text { with HE } \\
(\mathrm{n}=34)\end{array}$ & $\begin{array}{l}\text { Total } \\
(\mathrm{n}=67)\end{array}$ \\
\hline Age, mean (SD) & $51.9(12.7)$ & $54.6(11.6)$ & $53.3(12.2)$ \\
\hline \multicolumn{4}{|l|}{ Gender, N (\%) } \\
\hline Male & $20(61)$ & $21(62)$ & $41(61)$ \\
\hline Female & $13(39)$ & $13(38)$ & $26(39)$ \\
\hline \multicolumn{4}{|l|}{ Race, N (\%) } \\
\hline African American & $14(42)$ & $12(35)$ & $26(39)$ \\
\hline White & $14(42)$ & $16(47)$ & $30(45)$ \\
\hline Hispanic & $4(12)$ & $6(18)$ & $10(15)$ \\
\hline Other & $1(3)$ & 0 & $1(1)$ \\
\hline \multicolumn{4}{|l|}{ Marital status, N (\%) } \\
\hline Never married & $6(18)$ & $10(29)$ & $16(24)$ \\
\hline Married & $18(55)$ & $12(35)$ & $30(45)$ \\
\hline Divorced & $6(18)$ & $6(18)$ & $12(18)$ \\
\hline Separated & $2(6)$ & $3(9)$ & $5(7)$ \\
\hline Widowed & $1(3)$ & $3(9)$ & $4(6)$ \\
\hline \multicolumn{4}{|l|}{ Education level, N (\%) } \\
\hline High school or less & $11(33)$ & $11(33)$ & $22(33)$ \\
\hline Some college & $15(46)$ & $12(35)$ & $27(40)$ \\
\hline Graduated from college & $5(15)$ & $5(14)$ & $10(15)$ \\
\hline $\begin{array}{l}\text { Graduate education after } \\
\text { college }\end{array}$ & $2(6)$ & $6(18)$ & $8(12)$ \\
\hline \multicolumn{4}{|l|}{ Annual family income, $\mathrm{N}(\%)$} \\
\hline$<\$ 30,000$ & $14(42)$ & $15(45)$ & $29(43)$ \\
\hline$\$ 31,000-\$ 60,000$ & $10(30)$ & $7(21)$ & $17(25)$ \\
\hline$>\$ 60,000$ & $9(27)$ & $12(35)$ & $21(31)$ \\
\hline \multicolumn{4}{|l|}{ Diagnosis, N (\%) } \\
\hline $\begin{array}{l}\text { Acute lymphoblastic } \\
\text { leukemia }\end{array}$ & $2(6)$ & $2(6)$ & $4(6)$ \\
\hline $\begin{array}{l}\text { Acute myelogenous } \\
\text { leukemia }\end{array}$ & $7(21)$ & $7(20)$ & $14(21)$ \\
\hline $\begin{array}{l}\text { Chronic lymphocytic } \\
\text { leukemia }\end{array}$ & $1(3)$ & $1(3)$ & $2(4)$ \\
\hline $\begin{array}{l}\text { Chronic myelogenous } \\
\text { leukemia }\end{array}$ & $2(6)$ & $1(3)$ & $3(4)$ \\
\hline Hodgkin lymphoma & $2(6)$ & 0 & $2(3)$ \\
\hline non-Hodgkin lymphoma & $5(15)$ & $3(9)$ & $8(12)$ \\
\hline Multiple myeloma & $12(36)$ & $16(47)$ & $28(42)$ \\
\hline Myelodysplastic syndrome & $2(6)$ & $4(12)$ & $6(8)$ \\
\hline \multicolumn{4}{|l|}{ Donor type, N (\%) } \\
\hline Autologous & $20(61)$ & $19(56)$ & $39(58)$ \\
\hline Sibling & $4(31)$ & $6(40)$ & $10(36)$ \\
\hline Matched unrelated donor & $8(61)$ & $8(53)$ & $16(57)$ \\
\hline Haplo-identical & $1(8)$ & $1(7)$ & $2(7)$ \\
\hline $\begin{array}{l}\text { Length of hospitalization } \\
\text { (HCT to discharge, } \\
\text { mean (SD) }\end{array}$ & $16.7(4.2)$ & $18.1(5.5)$ & $17.4(4.9)$ \\
\hline $\begin{array}{l}\text { No. (\%) of subjects readmitted } \\
\text { to hospital during post- } \\
\text { hospital intervention phase }\end{array}$ & $3(9 \%)$ & $8(23 \%)$ & $11(16 \%)$ \\
\hline
\end{tabular}

$($ STEER group $=20$; UC + AC with HE group $=19)$. Twentyeight subjects received an allogeneic transplant (STEER group $=13$; $U C+A C$ with HE group $=15$ ). There were no differences between groups on any of the demographic data or clinical characteristics. The means and standard deviations for physical activity, fatigue, muscle strength, and functional ability are presented in Table 2 and QOL variables in Table 3.

\section{Compliance with STEER and UC + AC with HE}

Subjects assigned to the STEER arm were asked to complete 18 moderate-intensity strength training sessions after hospitalization (approximately 1 supervised session per week depending on scheduled clinic visits and 2 unsupervised visits per week for 6 weeks for a total of 18 sessions). The mean compliance rate for exercise session completion was $83 \%$. Seventy-two percent of subjects $(n=24)$ completed between
$80 \%$ and $100 \%$ of sessions. Only 1 subject failed to complete any of the exercise sessions after hospital discharge. Three subjects completed between $40 \%$ and $59 \%$ of sessions and 5 completed between $60 \%$ and $79 \%$. Subjects assigned to the $\mathrm{UC}+\mathrm{AC}$ with HE were asked to complete 6 educational sessions ( 1 session per week for 6 weeks). The mean compliance rate for the health education sessions was $97 \%$. Ninety-one percent $(n=31)$ completed all 6 educational sessions. One subjected completed 3 educational sessions, 1 completed 4, and 1 completed 5.

\section{Physical Activity}

Objectively measured physical activity

The main effects of group, $\mathrm{F}(1,65)=3.913, P=.05$, and time, $\mathrm{F}(1,65)=12.210, P=.001$, were significant. The STEER group was significantly more physically active than the UC + AC with HE group. Subjects in both groups experienced a significant reduction in physical activity baseline compared with after intervention. The STEER group experienced a $15 \%$ reduction in physical activity whereas the UC + AC with $\mathrm{HE}$ group experienced a $25 \%$ reduction, resulting in a $10 \%$ difference between the 2 groups. The group $\times$ time interaction was not significant, $\mathrm{F}(1,65)=.295$.

\section{Self-reported physical activity}

The main effects of group, $F(1,65)=.877$; time, $F(1$, $65)=1.151$; and group $\times$ time, $F(1,65)=.502$, were not significant.

\section{Fatigue}

Overall fatigue

The group $\times$ time interaction effect for overall fatigue was significant, $F(1,65)=4.380, P=.04$ (Figure 2). Tests of simple main effects revealed that the UC + AC with HE reported significantly increased overall fatigue from baseline to after intervention, $\mathrm{t}(33)=-2.174, P=.04$, while the STEER group reported improvements in fatigue from baseline to after intervention, although this was not significant. The main effects of group, $F(1,65)=.005$, and time, $F(1,65)=.355$, were not significant.

\section{Mental fatigue}

Mental fatigue followed a similar pattern. The group $\times$ time interaction effect for mental fatigue was significant, $\mathrm{F}$ ( 1 , $65)=6.524, P=.01$, (Figure 2 ). Tests of simple main effects revealed that the STEER group reported significant improvements in mental fatigue baseline to after intervention, $\mathrm{t}(32)=2.131, P=.04$, while the $\mathrm{UC}+\mathrm{AC}$ with HE reported increased fatigue from baseline to after intervention although this was not significant. The main effects of group, $\mathrm{F}$ $(1,65)=.313$; and time, $F(1,65)=.245$, for mental fatigue were not significant.

\section{Physical fatigue}

The main effects of group, $\mathrm{F}(1,65)=.049$; time, $\mathrm{F}(1$, $65)=2.114$; and, group $\times$ time interaction, $\mathrm{F}(1,65)=1.921$, for physical fatigue were not significant.

Fatigue subscale of the EORTC QLQ C-30

The main effects of group, $F(1,65)=.003$; time, $F(1$, $65)=1.704$; and group $\times$ time interaction, $F(1,65)=.174$, for 
Table 2

Means (SD) of Physical Activity, Fatigue, Muscle Strength, and Functional Ability; STEER $(\mathrm{n}=33)$ compared to UC + AC with HE $(\mathrm{n}=34)$

\begin{tabular}{|c|c|c|c|c|c|}
\hline Variable & $\begin{array}{l}\text { Baseline } \\
\text { Mean (SD) }\end{array}$ & $\begin{array}{l}\text { Post Intervention } \\
\text { Mean (SD) }\end{array}$ & $\begin{array}{l}\text { Group Effect } \\
P \text { Value }\end{array}$ & $\begin{array}{l}\text { Time Effect } \\
P \text { Value }\end{array}$ & $\begin{array}{l}\text { Interaction Effect } \\
P \text { Value }\end{array}$ \\
\hline \multicolumn{6}{|l|}{ Physical activity } \\
\hline Self-reported physical activity (Godin) & & & NS & NS & NS \\
\hline STEER & $18.8(15.9)$ & $28.2(25.0)$ & & & \\
\hline $\mathrm{UC}+\mathrm{AC}$ with $\mathrm{HE}$ & $27.6(40.6)$ & $29.5(35.1)$ & & & \\
\hline Physical activity (average physical activity count per minute) & & & .05 & .001 & NS \\
\hline STEER & $214(131)$ & $182(113)$ & & & \\
\hline \multicolumn{6}{|l|}{ Fatigue } \\
\hline$\overline{\text { Overall fatigue (Chalder fatigue scale) }}$ & & & NS & NS & .04 \\
\hline STEER & $16.9(6.1)$ & $16.3(4.9)$ & & & \\
\hline $\mathrm{UC}+\mathrm{AC}$ with $\mathrm{HE}$ & $15.8(4.7)$ & $17.6(5.9)$ & & & \\
\hline Physical fatigue (Chalder fatigue scale) & & & NS & NS & NS \\
\hline STEER & $11.7(4.3)$ & $11.7(3.9)$ & & & \\
\hline $\mathrm{UC}+\mathrm{AC}$ with $\mathrm{HE}$ & $10.9(3.5)$ & $12.1(4.5)$ & & & \\
\hline Mental fatigue (Chalder fatigue scale) & & & NS & NS & .013 \\
\hline Fatigue (EORTC QLQ-C30) & & & NS & NS & NS \\
\hline STEER & $38.7(28.9)$ & $41.8(24.9)$ & & & \\
\hline $\mathrm{UC}+\mathrm{AC}$ with $\mathrm{HE}$ & $37.6(25.2)$ & $43.5(26.9)$ & & & \\
\hline \multicolumn{6}{|l|}{ Muscle strength } \\
\hline 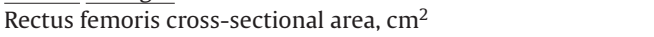 & & & NS & NS & NS \\
\hline STEER & $2.94(1.17)$ & $2.89(1.13)$ & & & \\
\hline $\mathrm{UC}+\mathrm{AC}$ with $\mathrm{HE}$ & $2.65(1.15)$ & $2.57(1.13)$ & & & \\
\hline Hand grip strength, kgs) & & & NS & $<.001$ & NS \\
\hline STEER & $34.06(10.74)$ & $31.12(10.26)$ & & & \\
\hline $\mathrm{UC}+\mathrm{AC}$ with $\mathrm{HE}$ & $31.37(10.58)$ & $27.54(11.07)$ & & & \\
\hline Arm curl test (repetitions in 30 seconds) & & & .099 & NS & .067 \\
\hline STEER & $17.46(6.05)$ & $18.03(6.01)$ & & & \\
\hline $\mathrm{UC}+\mathrm{AC}$ with $\mathrm{HE}$ & $16.29(4.67)$ & $14.97(5.45)$ & & & \\
\hline \multicolumn{6}{|l|}{ Functional ability } \\
\hline Timed stair climb, seconds & & & .074 & .012 & .029 \\
\hline STEER & $5.54(2.81)$ & $5.72(2.25)$ & & & \\
\hline $\mathrm{UC}+\mathrm{AC}$ with $\mathrm{HE}$ & $5.56(1.79)$ & $8.11(5.63)$ & & & \\
\hline $\mathrm{UC}+\mathrm{AC}$ with $\mathrm{HE}$ & $7.86(1.90)$ & $10.11(7.28)$ & & & \\
\hline Fifteen-foot walk time, seconds & & & .038 & .083 & .083 \\
\hline STEER & $3.28(1.01)$ & $3.27(.86)$ & & & \\
\hline $\mathrm{UC}+\mathrm{AC}$ with $\mathrm{HE}$ & $3.50(.73)$ & $4.10(1.92)$ & & & \\
\hline Thirty-second chair stand test, cycles in 30 seconds & & & NS & NS & NS \\
\hline STEER & $13.03(4.97)$ & $13.03(5.58)$ & & & \\
\hline $\mathrm{UC}+\mathrm{AC}$ with $\mathrm{HE}$ & $11.47(6.37)$ & $10.44(6.73)$ & & & \\
\hline Body weight, kilogram & & & NS & NS & NS \\
\hline STEER & $83.92(22.73)$ & $79.12(22.70)$ & & & \\
\hline $\mathrm{UC}+\mathrm{AC}$ with $\mathrm{HE}$ & $84.30(24.54)$ & 79.56 (24.09) & & & \\
\hline
\end{tabular}

NS indicates nonsignificant.

the fatigue subscale of the EORTC QLQ C-30 were not significant.

\section{Muscle Strength}

Rectus femoris cross-sectional area

The main effects of group, $\mathrm{F}(1,65)=1.213$; time, $\mathrm{F}(1$, $65)=1.639$; and group $\times$ time interaction, $F(1,65)=.124$, for the rectus femoris cross-sectional area were not significant.

\section{Hand grip strength}

The main effect of time was significant, $F(1,65)=33.556$, $P<.001$. Both groups experienced reductions in hand grip strength from baseline to after intervention. The main effects of group, $F(1,65)=1.528$, and group $\times$ time interaction, $F(1$, $65)=.581$, for hand grip strength were not significant.

Arm curls

The main effects of group, $F(1,65)=2.801$; time, $\mathrm{F}(1,65)=.537$; and group $\times$ time interaction, $\mathrm{F}(1,65)=3.464$,
$P=.067$, for arm curls were not significant. The group $\times$ time interaction effect approached significance, so tests of simple effects were performed. The STEER group was able to perform significantly more arm curls compared with the UC + AC with HE after intervention, $\mathrm{t}(65)=3.05971, P=.03$.

\section{Functional Ability}

Timed stair climb

The main effects of time, $\mathrm{F}(1,65)=6.643, P=.01$, and group $\times$ time interaction, $F(1,65)=5.014, P=.03$, for the timed stair climb were significant (Figure 3 ). Test of simple main effects revealed that the UC + AC with HE group's timed stair climb was significantly slower from baseline to after intervention, $\mathrm{t}(33)=-2.644, P=.01$, while the STEER group's time remained stable. Although there was no significant difference between groups at baseline, the STEER group was able to climb the stairs significantly faster after the intervention, $t$ $(44)=2.293, P=.03$. The group effect was not significant, $\mathrm{F}(1,65)=3.308$. 
Table 3

Means (SD) of QOL (EORTC QLQ C-30)

\begin{tabular}{|c|c|c|}
\hline QOL Variable & Baseline & After Intervention \\
\hline \multicolumn{3}{|l|}{$\begin{array}{l}\text { Global QOL/health } \\
\text { status }\end{array}$} \\
\hline STEER & $62.1(22.7)$ & $64.4(18.2)$ \\
\hline $\mathrm{UC}+\mathrm{AC}$ with $\mathrm{HE}$ & $61.5(21.0)$ & $62.5(24.9)$ \\
\hline \multicolumn{3}{|l|}{ Functional subscales } \\
\hline \multicolumn{3}{|l|}{ Physical } \\
\hline STEER & $78.6(26.2)$ & $79.4(18.9)$ \\
\hline $\mathrm{UC}+\mathrm{AC}$ with $\mathrm{HE}$ & $79.2(18.1)$ & $74.9(20.2)$ \\
\hline \multicolumn{3}{|l|}{ Emotional } \\
\hline STEER & $71.7(25.3)$ & $79.3(23.9)$ \\
\hline $\mathrm{UC}+\mathrm{AC}$ with $\mathrm{HE}$ & $74.0(21.2)$ & $74.0(25.4)$ \\
\hline \multicolumn{3}{|l|}{ Role } \\
\hline STEER & $70.2(32.2)$ & $74.7(28.3)$ \\
\hline $\mathrm{UC}+\mathrm{AC}$ with $\mathrm{HE}$ & $65.7(31.2)$ & $74.5(32.4)$ \\
\hline \multicolumn{3}{|l|}{ Cognitive } \\
\hline STEER & $83.3(21.7)$ & $86.9(17.6)$ \\
\hline $\mathrm{UC}+\mathrm{AC}$ with $\mathrm{HE}$ & $84.3(17.9)$ & $78.9(22.1)$ \\
\hline \multicolumn{3}{|l|}{ Social } \\
\hline STEER & $67.7(33.1)$ & $72.2(31.1)$ \\
\hline $\mathrm{UC}+\mathrm{AC}$ with $\mathrm{HE}$ & $74.5(26.7)$ & $70.1(31.7)$ \\
\hline \multicolumn{3}{|l|}{ Symptoms subscales } \\
\hline \multicolumn{3}{|l|}{ Pain } \\
\hline STEER & $26.8(27.9)$ & $25.3(31.8)$ \\
\hline $\mathrm{UC}+\mathrm{AC}$ with $\mathrm{HE}$ & $33.8(30.3)$ & $34.8(33.7)$ \\
\hline \multicolumn{3}{|l|}{ Nausea/vomiting } \\
\hline STEER & $8.1(22.1)$ & $17.7(29.7)$ \\
\hline $\mathrm{UC}+\mathrm{AC}$ with $\mathrm{HE}$ & $10.3(18.4)$ & $10.3(19.3)$ \\
\hline \multicolumn{3}{|l|}{ Single items } \\
\hline \multicolumn{3}{|l|}{ Appetite loss } \\
\hline STEER & $20.2(31.1)$ & $22.2(33.0)$ \\
\hline $\mathrm{UC}+\mathrm{AC}$ with $\mathrm{HE}$ & $20.6(26.0)$ & $28.4(35.9)$ \\
\hline \multicolumn{3}{|l|}{ Constipation } \\
\hline STEER & $11.1(27.2)$ & $8.1(22.1)$ \\
\hline $\mathrm{UC}+\mathrm{AC}$ with $\mathrm{HE}$ & $8.8(17.0)$ & $9.8(19.3$ \\
\hline \multicolumn{3}{|l|}{ Dyspnea } \\
\hline STEER & $23.2(35.8)$ & $20.2(28.8)$ \\
\hline $\mathrm{UC}+\mathrm{AC}$ with $\mathrm{HE}$ & $18.6(24.9)$ & $21.6(25.8)$ \\
\hline \multicolumn{3}{|l|}{ Diarrhea } \\
\hline STEER & $14.1(28.9)$ & $10.1(17.6)$ \\
\hline $\mathrm{UC}+\mathrm{AC}$ with $\mathrm{HE}$ & $11.8(25.8)$ & $11.8(27.1)$ \\
\hline \multicolumn{3}{|l|}{ Financial impact } \\
\hline STEER & $39.4(32.8)$ & $28.3(36.4)$ \\
\hline $\mathrm{UC}+\mathrm{AC}$ with $\mathrm{HE}$ & $33.3(41.0)$ & $29.4(36.5)$ \\
\hline \multicolumn{3}{|l|}{ Sleep disturbances } \\
\hline STEER & $32.3(36.8)$ & $37.4(38.9)$ \\
\hline $\mathrm{UC}+\mathrm{AC}$ with $\mathrm{HE}$ & $43.1(35.3)$ & $39.2(37.1)$ \\
\hline
\end{tabular}

Data presented are mean (SD).
Timed up and go

The main effects of group, $\mathrm{F}(1,65)=4.885, P=.03$, and group $\times$ time interaction, $\mathrm{F}(1,65)=3.940, P=.05$, for the timed and up were significant (Figure 3 ). Test of simple main effects revealed that the UC + AC with HE group was slower from baseline to after intervention (approached significance), $\mathrm{t}$ (33) $=-1.921, P=.06$, while the STEER group's time remained stable. After the intervention, the STEER group was able to complete the timed up and go test faster than the $\mathrm{UC}+\mathrm{AC}$ with HE, $\mathrm{t}(46)=2.274, P=.03$. There was no significant difference between groups at baseline. The time effect was not significant, $F(1,65)=3.133$.

\section{Fifteen-foot walk time}

The main effect of group, $\mathrm{F}(1,65)=4.481, P=.04$, was significant. The STEER group completed the 15 -foot walk time faster. The main effects of time, $F(1,65)=3.095$, and group $\times$ time interaction, $F(1,65)=3.108$, were not significant. The time and group $\times$ time interaction effects approached significance $(P=.08)$. As a result, test of simple effects were conducted. The UC $+\mathrm{AC}$ with HE group's walk time was slower, approaching significance, from baseline to after intervention, $\mathrm{t}(33)=-1.921, P=.06$. There was no significant difference in walk time for the STEER group baseline to after intervention. At baseline, no significant differences between groups were detected. After the intervention, the STEER group was significantly faster than the UC + AC with HE, $\mathrm{t}(46)=2.274$, $P=.02$.

Thirty-second sit to stand

The main effects of group, $F(1,65)=2.337$; time, $F(1$, $65)=.946$; and group $\times$ time interaction, $\mathrm{F}(1,65)=.946$, for the 30 -second sit to stand were not significant.

\section{QOL}

Means and standard deviations for the global QOL subscale, 5 functional subscales, 3 symptom subscales, or single items are displayed in Table 3. None of these resulted in significant group, time, or group $\times$ time interaction effects.

\section{DISCUSSION}

Intensive cancer treatment followed by HCT is potentially curative but associated with substantial short- and longterm adverse effects. Effective pragmatic interventions during the early recovery period are urgently needed to alleviate
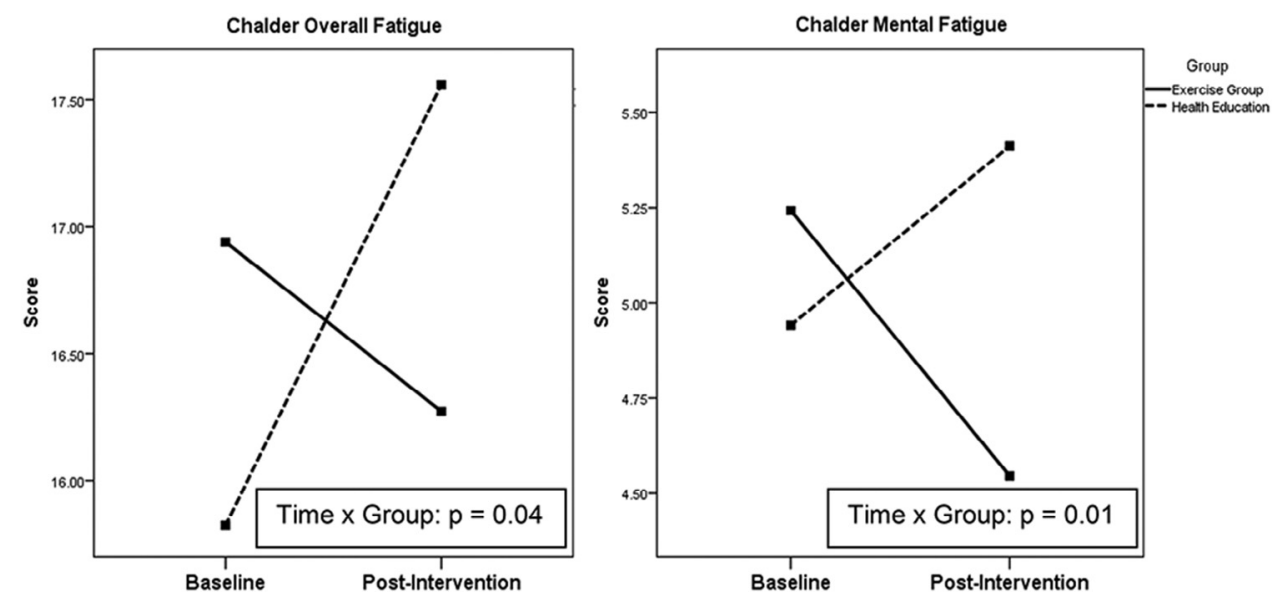

Figure 2. Fatigue. 

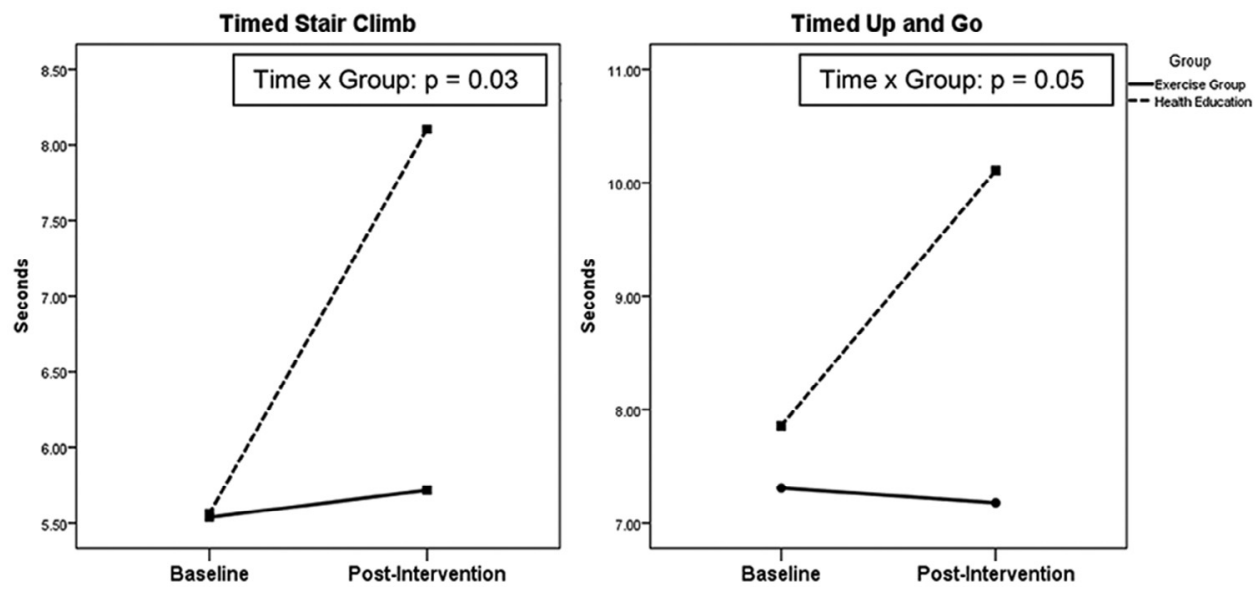

Figure 3. Functional ability.

symptoms, promote functional independence, and improve QOL. The findings from this single-blind RCT demonstrate the beneficial effects of a strength training program after HCT on physical activity, fatigue, muscle strength, and functional ability compared with UC + AC with HE. Importantly, these positive effects were demonstrated while controlling for the time, attention, and interpersonal communication received by the STEER group through the use of an appropriate control group. The findings provide support for our model that maintaining muscle mass through strength training effectively reduces fatigue and maintains and/or improves muscle strength and functional ability after intensive cancer treatment and HCT. Although the exact recovery patterns between groups and over time varied, the STEER group either maintained or improved their health status from baseline to after intervention whereas the US + AC with HE group generally declined over time.

This study, focused solely on strength training during the acute recovery period, contributes to a growing body of exercise research after HCT and addresses a known gap in the literature. To demonstrate the effectiveness of strength training, we hypothesized that significant group $\times$ time interactions would be found. As expected, strength training preferentially improved fatigue and functional ability (timed stair climb and timed up and go) as demonstrated by the significant interactions effects with trends toward improving muscle strength (arm curls). This provides evidence that a 6-week moderate-intensity strength training program may be a viable option for enhancing early recovery after HCT. The findings are novel as only 1 RCT, besides our pilot work, tested singlemodality strength training [28]. The Cunningham study did not assess fatigue or functional ability and the exercise intervention focused on inpatient strength training (up to day 35 after transplantation).

We expected to find significant interaction effects for physical activity, muscle strength (cross-sectional area of the rectus femoris and hand grip) and QOL. We found the following: (1) group and time effects for physical activity, (2) time effects for hand grip strength, and (3) no effects for QOL or changes in muscle mass as measured by the rectus femoris crosssectional area. As expected, the STEER group was more physically active as demonstrated by the group effect and only experienced a $15 \%$ decline in physical activity after intervention compared with a $25 \%$ drop in the control group. A significant interaction effect, however, was not found. There are several potential reasons for this. First, our strength training intervention may not have been strong enough to produce a significant interaction effect. Second, objective physical activity may not be captured adequately by wearing devices on the wrist. Third, the control group may have consciously attempted to increase physical activity levels in the posttransplantation period as evidenced by their reports of leisuretime physical activity. The control group reported more leisure-time physical activity at baseline and after intervention compared with the strength training group. The results from the objective physical activity assessments, however, indicate that the strength training group was more physically active. The reasons for the discrepancy between objectively measured and self-reported physical activity is not clear but requires further investigation. Importantly, subjects assigned to the control group were not told that they could not exercise as this would have been unethical. Finally, the intervention may have no effect on physical activity as the main effect of strength training is to build and/or maintain muscle strength.

The results for increasing physical activity through exercise in the HCT literature are mixed. Consistent with our findings, Knoll et al. reported that a 12-week outpatient exercise program, incorporating aerobic and strength exercises, compared with usual care did not result in a group $\times$ time interaction effect for self-reported physical activity [21]. Conversely, Jacobsen et al. conducted a large $(n=711) 4$-arm study comparing a self-directed exercise program with a selfadministered stress management program, a self-directed exercise program plus self-administered stress management, and usual care [86]. The exercise intervention was selfdirected after a brief 20-minute introduction to the program. Those assigned to the exercise group increased their physical activity (as measured by the leisure score of the Godin leisure-time exercise questionnaire) 6 months after the intervention but not at day 30,60 , or 100 . The reason for the delayed response is not clear. Although it seems logical that exercise would lead to increased physical activity, the mixed results suggest that further research is needed. In addition, it would be prudent to collect self-reported as well as objectively measured physical activity given the discrepancies between the 2 in our study.

HCT recipients represent an understudied group even though they may be one of the neediest, in terms of physical deconditioning after cancer treatment. Two meta-analysis 
evaluating exercise after HCT identified positive effects across a range of potential outcomes, such as fatigue, muscle strength, and QOL $[18,19]$. These analyses, however, only included 8 [18] and 11 [19] RCTs, demonstrating the continued need for investigation. Furthermore, small sample sizes, heterogeneity of exercise interventions, timing differences related to exercise initiation, among other factors, make it very difficult to effectively combine results across studies; and, ultimately identify the pillars of an ideal exercise program after HCT. An exercise program for people in the acute recovery phase may need to be vastly different than that developed for long-term survivors.

The importance of developing effective and pragmatic exercise interventions after HCT cannot be overstated to increase the likelihood of translation into clinical practice, if successful. Our STEER intervention is innovative as it was tested in a challenging group of patients during a period of complex and frequently changing health care needs and because it integrated seamlessly into existing clinical practice settings, which is unique and patient centered. Implementing an exercise program into any clinical practice is challenging and is even more so in this population. STEER was designed to maximize benefits and minimize burdens in research subjects by taking advantage of common clinical situations after HCT, such as frequent clinic visits during the first 6 weeks after hospital discharge and downtime in the clinic when waiting to see health care providers. Using the downtime in clinic to exercise after hospitalization is an efficient use of the subject's time that does not extend clinic visits and may increase patient satisfaction although we did not measure this. Elastic resistance bands were used instead of free weights as they are very portable and unlikely to cause harm if dropped. Self-efficacy to exercise was promoted by providing instruction and simulating the exercises without bands during hospitalization. This also helped build rapport with subjects before beginning the moderate-intensity strength training. The compliance with the moderate-intensity program conducted after hospital discharge was high (83\%), demonstrating acceptability of the intervention and effective tailoring to the subject's capabilities. In this study, our goal was to a balance between intensity of the intervention, making it strong enough to exert an effect on important variables, such as fatigue and functional ability, yet simple enough for eventual scalability.

This study findings provides direction for multiple avenues of scholarship. Continuing this line of inquiry, further research is needed, such as testing STEER in larger samples, across multiple sites and monitoring subjects over longer periods of time to determine sustainability of effects. Our study only followed subjects to the end of the 6-week intervention; this is a limitation of our study. In our next study, we plan to implement the intervention over 12 weeks and follow subjects for 6 months to determine the longer-term effects and sustainability of the strength training intervention. The use of different comparison groups may also influence study findings. In this study, we stringently controlled for the time, attention, and interpersonal communication received by the STEER group. Our control arm contained a potentially active ingredient, standardized health education, and this may have confounded our ability to find QOL effects. Compliance in the control arm was very high for the 6 educational sessions (over 97\%), demonstrating acceptability. To promote high subject retention in the control group, as was the case in our study, it may be important that HCT subjects assigned to the control arm receive an intervention perceived to be valuable to their health, but this may come at the expense of finding significant results for important variables.

\section{CONCLUSION}

A moderate-intensity 6-week strength training intervention enhances early recovery after HCT; reducing fatigue while maintaining and/or improving muscle strength and function ability. The recovery patterns for the strength training and $\mathrm{UC}+\mathrm{AC}$ with HE groups varied. The strength training group generally improved or stayed the same over time while the UC + AC with HE group generally declined. Significant differences between the groups were found after intervention. The strength training intervention, specifically designed to maximize benefits to subjects while minimizing burdens, was integrated seamlessly into existing clinical practice settings. A balanced approach to developing exercise interventions is needed for HCT recipients; making it strong enough to effect outcomes, simple enough to minimize subject burdens, and relatively straightforward and uncomplicated to facilitate translation into clinical practice.

\section{ACKNOWLEDGMENTS}

This work was supported by the American Cancer Society, Research Scholar Grant (E. Hacker, PI, RSG-13-054-01-PCSM). Financial disclosure: The authors have nothing to disclose.

Conflict of interest statement: There are no conflicts of interest to report.

\section{REFERENCES}

1. Pasquini MC, Zhu X. Current use and outcome of hematopoietic stem cell transplantation: CIBMTR Summary Slides, 2015. Available at: http://www.cibmtr.org. Accessed September 1, 2016.

2. Labrador J, Lopez-Corral L, Vazquez L, et al. Incidence and risk factors for life-threatening bleeding after allogeneic stem cell transplant. $\mathrm{Br} \mathrm{J}$ Haematol. 2015;169:719-725.

3. Copelan EA. Hematopoietic stem-cell transplantation. N Engl J Med. 2006;354:1813-1826.

4. Syrjala KL, Langer SL, Abrams JR, Storer BE, Martin PJ. Late effects of hematopoietic cell transplantation among 10-year adult survivors compared with case-matched controls. J Clin Oncol. 2005;23:6596-6606.

5. Bergkvist K, Winterling J, Johansson E, et al. General health, symptom occurrence, and self-efficacy in adult survivors after allogeneic hematopoietic stem cell transplantation: a cross-sectional comparison between hospital care and home care. Support Care Cancer. 2015; 23:1273-1283.

6. Cohen MZ, Rozmus CL, Mendoza TR, et al. Symptoms and quality of life in diverse patients undergoing hematopoietic stem cell transplantation. J Pain Symptom Manage. 2012;44:168-180.

7. Grulke N, Albani C, Bailer H. Quality of life in patients before and after haematopoietic stem cell transplantation measured with the European Organization for Research and Treatment of Cancer (EORTC) Quality of Life Core Questionnaire QLQ-C30. Bone Marrow Transplant. 2012;47:473482.

8. Hacker ED, Ferrans C, Verlen E, et al. Fatigue and physical activity in patients undergoing hematopoietic stem cell transplant. Oncol Nurs Forum. 2006;33:614-624.

9. Sherman AC, Simonton S, Latif U, Plante TG, Anaissie EJ. Changes in quality-of-life and psychosocial adjustment among multiple myeloma patients treated with high-dose melphalan and autologous stem cell transplantation. Biol Blood Marrow Transplant. 2009;15:12-20.

10. Andersson I, Ahlberg K, Stockelberg D, Brune M, Persson LO. Healthrelated quality of life in patients undergoing allogeneic stem cell transplantation after reduced intensity conditioning versus myeloablative conditioning. Cancer Nurs. 2009;32:325-334.

11. Mosher CE, Redd WH, Rini CM, Burkhalter JE, DuHamel KN. Physical, psychological, and social sequelae following hematopoietic stem cell transplantation: a review of the literature. Psychooncology. 2009;18:113127.

12. Bevans MF, Mitchell SA, Marden S. The symptom experience in the first 100 days following allogeneic hematopoietic stem cell transplantation (HSCT). Support Care Cancer. 2008;16:1243-1254.

13. Schulte CM, Beelen DW. Low pretransplant bone-mineral density and rapid bone loss do not increase risk for avascular osteonecrosis after 
allogeneic hematopoietic stem cell transplantation. Transplantation. 2005;79:1748-1755.

14. Kyle UG, Chalandon Y, Miralbell R, et al. Longitudinal follow-up of body composition in hematopoietic stem cell transplant patients. Bone Marrow Transplant. 2005;35:1171-1177.

15. Morishita S, Kaida K, Tanaka T, et al. Prevalence of sarcopenia and relevance of body composition, physiological function, fatigue, and health-related quality of life in patients before allogeneic hematopoietic stem cell transplantation. Support Care Cancer. 2012;20:3161-3168.

16. Fried LP, Tangen CM, Walston J, et al. Frailty in older adults: evidence for a phenotype. J Gerontol A Biol Sci Med Sci. 2001;56:M146-M156.

17. Syrjala KL, Chapko MK, Vitaliano PP, Cummings C, Sullivan KM. Recovery after allogeneic marrow transplantation: prospective study of predictors of long-term physical and psychosocial functioning. Bone Marrow Transplant. 1993;11:319-327.

18. Persoon S, Kersten MJ, van der Weiden K, et al. Effects of exercise in patients treated with stem cell transplantation for a hematologic malignancy: a systematic review and meta-analysis. Cancer Treat Rev. 2013;39:682-690.

19. van Haren IE, Timmerman H, Potting CM, Blijlevens NM, Staal JB, Nijhuis-van der Sanden MW. Physical exercise for patients undergoing hematopoietic stem cell transplantation: systematic review and metaanalyses of randomized controlled trials. Phys Ther 2013:93:514-528.

20. American College of Sports Medicine Position Stand. The recommended quantity and quality of exercise for developing and maintaining cardiorespiratory and muscular fitness, and flexibility in healthy adults. Med Sci Sports Exerc. 1998;30:975-991.

21. Knols RH, de Bruin ED, Uebelhart D, et al. Effects of an outpatient physical exercise program on hematopoietic stem-cell transplantation recipients: a randomized clinical trial. Bone Marrow Transplant 2011:46:1245-1255.

22. Coleman EA, Coon S, Hall-Barrow J, Richards K, Gaylor D, Stewart B. Feasibility of exercise during treatment for multiple myeloma. Cancer Nurs. 2003;26:410-419.

23. Coleman EA, Coon SK, Kennedy RL, et al. Effects of exercise in combination with epoetin alfa during high-dose chemotherapy and autologous peripheral blood stem cell transplantation for multiple myeloma. Oncol Nurs Forum. 2008;35:E53-E61.

24. Shelton ML, Lee JQ, Morris GS, et al. A randomized control trial of a supervised versus a self-directed exercise program for allogeneic stem cell transplant patients. Psychooncology. 2009;18:353-359.

25. Jarden M, Baadsgaard MT, Hovgaard DJ, Boesen E, Adamsen L. A randomized trial on the effect of a multimodal intervention on physical capacity, functional performance and quality of life in adult patients undergoing allogeneic SCT. Bone Marrow Transplant 2009:43:725-737.

26. Mello M, Tanaka C, Dulley FL. Effects of an exercise program on muscle performance in patients undergoing allogeneic bone marrow transplantation. Bone Marrow Transplant. 2003;32:723-728.

27. Wiskemann J, Dreger P, Schwerdtfeger R, et al. Effects of a partly self-administered exercise program before, during, and after allogeneic stem cell transplantation. Blood. 2011;117:2604-2613.

28. Cunningham BA, Morris G, Cheney CL, Buergel N, Aker SN, Lenssen P. Effects of resistive exercise on skeletal muscle in marrow transplant recipients receiving total parenteral nutrition. JPEN J Parenter Enteral Nutr. 1986;10:558-563.

29. Hacker ED, Larson J, Kujath A, Peace D, Rondelli D, Gaston L. Strength training following hematopoietic stem cell transplantation. Cancer Nurs. 2011;34:238-249.

30. Hacker ED, Larson JL, Peace D. Exercise in patients receiving hematopoietic stem cell transplantation: lessons learned and results from a feasibility study. Oncol Nurs Forum. 2011;38:216-223.

31. Schmitz KH, Courneya KS, Matthews C, et al. American College of Sports Medicine roundtable on exercise guidelines for cancer survivors. Med Sci Sports Exerc. 2010;42:1409-1426.

32. Doig GS, Simpson F. Randomization and allocation concealment: a practical guide for researchers. J Crit Care. 2005;20:187-191. Discussion 191-3.

33. Borg G. Borg's Perceived Exertion and Pain Scales. Stockholm: Human Kinetics; 1998.

34. Skelton DA, Young A, Greig CA, Malbut KE. Effects of resistance training on strength, power, and selected functional abilities of women aged 75 and older. J Am Geriatr Soc. 1995;43:1081-1087.

35. Topp R, Mikesky A, Dayhoff NE, Holt W. Effect of resistance training on strength, postural control, and gait velocity among older adults. Clin Nurs Res. 1996;5:407-427

36. Jette AM, Harris BA, Sleeper $L$, et al. A home-based exercise program for nondisabled older adults. J Am Geriatr Soc. 1996;44:644-649.

37. Damush TM, Damush JG Jr. The effects of strength training on strength and health-related quality of life in older adult women. Gerontologist. 1999;39:705-710.

38. Bang MD, Deyle GD. Comparison of supervised exercise with and without manual physical therapy for patients with shoulder impingement syndrome. J Orthop Sports Phys Ther. 2000;30:126-137.

39. Deyle GD, Henderson NE, Matekel RL, Ryder MG, Garber MB, Allison SC Effectiveness of manual physical therapy and exercise in osteoarthritis of the knee. A randomized, controlled trial. Ann Intern Med. 2000; 132:173-181.

40. Wang $\mathrm{CH}$, McClure P, Pratt NE, Nobilini R. Stretching and strengthening exercises: their effect on three-dimensional scapular kinematics. Arch Phys Med Rehabil. 1999;80:923-929.

41. Verrill DE, Ribisl PM. Resistive exercise training in cardiac rehabilitation. An update. Sports Med. 1996;21:347-383.

42. Godin G, Shephard RJ. A simple method to assess exercise behavior in the community. Can J Appl Sport Sci. 1985;10:141-146.

43. Esliger DW, Tremblay MS. Technical reliability assessment of three accelerometer models in a mechanical setup. Med Sci Sports Exerc. 2006;38:2173-2181.

44. Steele BG, Holt L, Belza B, Ferris S, Lakshminaryan S, Buchner DM. Quantitating physical activity in COPD using a triaxial accelerometer. Chest. 2000;117:1359-1367.

45. Berger AM. Patterns of fatigue and activity and rest during adjuvant breast cancer chemotherapy. Oncol Nurs Forum. 1998;25:51-62.

46. Miaskowski C, Lee KA. Pain, fatigue, and sleep disturbances in oncology outpatients receiving radiation therapy for bone metastasis: a pilot study. J Pain Symptom Manage. 1999;17:320-332.

47. Sarna L, Conde F. Physical activity and fatigue during radiation therapy: a pilot study using actigraph monitors. Oncol Nurs Forum. 2001;28:10431046.

48. Andrykowski MA, Beacham AO, Jacobsen PB. Prospective, longitudinal study of leisure-time exercise in women with early-stage breast cancer. Cancer Epidemiol Biomarkers Prev. 2007; 16:430-438.

49. Snook EM, Motl RW, Gliottoni RC. The effect of walking mobility on the measurement of physical activity using accelerometry in multiple sclerosis. Clin Rehabil. 2009;23:248-258.

50. Miller DJ, Freedson PS, Kline GM. Comparison of activity levels using the Caltrac accelerometer and five questionnaires. Med Sci Sports Exerc. 1994;26:376-382.

51. Chalder T, Berelowitz G, Pawlikowska T, et al. Development of a fatigue scale. J Psychosom Res. 1993:37:147-153.

52. Aaronson NK, Ahmedzai S, Bergman B, et al. The European Organization for Research and Treatment of Cancer QLQ-C30: a quality of life instrument for use in international clinical trials in oncology. J Natl Cancer Inst. 1993;85:365-376.

53. Loge JH, Abrahamsen AF, Ekeberg O, Kaasa S. Hodgkin's disease survivors more fatigued than the general population. J Clin Oncol. 1999;17:253261.

54. Cella M, Chalder T. Measuring fatigue in clinical and community settings. J Psychosom Res. 2010;69:17-22.

55. Loge $\mathrm{JH}$, Ekeberg $\mathrm{O}$, Kaasa S. Fatigue in the general Norwegian population: normative data and associations. J Psychosom Res. 1998;45:53-65.

56. Aaronson NK, Cull AN, Kaasa S, Sprangers MA. Quality of Life and Pharmacoeconomics. 2nd ed. Philadelphia: Lipponcott-Raven; 1996.

57. Hacker ED, Peters T, Garkova M. Ultrasound assessment of the rectus femoris cross-sectional area: subject position implications. West J Nurs Res. 2016:38:1221-1230.

58. Gruther W, Benesch T, Zorn C, et al. Muscle wasting in intensive care patients: ultrasound observation of the M. quadriceps femoris muscle layer. J Rehabil Med. 2008;40:185-189.

59. Hammond K, Mampilly J, Laghi FA, et al. Validity and reliability of rectus femoris ultrasound measurements: comparison of curved-array and linear-array transducers. J Rehabil Res Dev. 2014;51:1155-1164.

60. Seymour JM, Ward K, Sidhu PS, et al. Ultrasound measurement of rectus femoris cross-sectional area and the relationship with quadriceps strength in COPD. Thorax. 2009;64:418-423.

61. Uremovic M, Pasic MB, Seric V, et al. Ultrasound measurement of the volume of musculus quadriceps after knee joint injury. Coll Antropol. 2004;28(suppl 2):227-233.

62. Giles LS, Webster KE, McClelland JA, Cook J. Can ultrasound measurements of muscle thickness be used to measure the size of individual quadriceps muscles in people with patellofemoral pain? Phys Ther Sport. 2015;16:45-52.

63. Mathiowetz V, Rennells C, Donahoe L. Effect of elbow position on grip and key pinch strength. J Hand Surg Am. 1985;10:694-697.

64. Trossman PB, Suleski KB, Li PW. Test-retest reliability and day to day variability of an isometric grip strength test using the work simulator. Occup Ther I Res. 1990;10:266-279.

65. Reddon JR, Stefanyk WO, Gill DM, Renney C. Hand dynamometer: effects of trials and sessions. Percept Mot Skills. 1985;61(3 Pt 2):1195-1198.

66. Balogun JA, Akomolafe CT, Amusa LO. Grip strength: effects of testing posture and elbow position. Arch Phys Med Rehabil. 1991;72:280-283.

67. Kallman DA, Plato CC, Tobin JD. The role of muscle loss in the age-related decline of grip strength: cross-sectional and longitudinal perspectives. J Gerontol. 1990;45:M82-M88.

68. Martin S, Neale G, Elia M. Factors affecting maximal momentary grip strength. Hum Nutr Clin Nutr. 1985;39:137-147.

69. Purath J, Buchholz SW, Kark DL. Physical fitness assessment of older adults in the primary care setting. J Am Acad Nurse Pract. 2009;21:101107 
70. Rikli RE, Jones CJ. Senior Fitness Test Manual. Champaign, IL: Human Kinetics; 2001.

71. Benton MJ, Alexander JL. Validation of functional fitness tests as surrogates for strength measurement in frail, older adults with chronic obstructive pulmonary disease. Am J Phys Med Rehabil. 2009;88:579-583. quiz 584-6, 590.

72. Sowers M, Jannausch ML, Gross M, et al. Performance-based physical functioning in African-American and Caucasian women at midlife: considering body composition, quadriceps strength, and knee osteoarthritis. Am J Epidemiol. 2006;163:950-958.

73. Nyland J, Frost K, Quesada P, et al. Self-reported chair-rise ability relates to stair-climbing readiness of total knee arthroplasty patients: a pilot study. J Rehabil Res Dev. 2007;44:751-759.

74. Salem GJ, Wang MY, Young JT, Marion M, Greendale GA. Knee strength and lower- and higher-intensity functional performance in older adults. Med Sci Sports Exerc. 2000;32:1679-1684.

75. Podsiadlo D, Richardson S. The timed "Up \& Go": a test of basic functional mobility for frail elderly persons. J Am Geriatr Soc. 1991;39:142-148.

76. Spagnuolo DL, Jurgensen SP, Iwama AM, Dourado VZ. Walking for the assessment of balance in healthy subjects older than 40 years. Gerontology. 2010;56:467-473.

77. Bischoff HA, Stahelin HB, Monsch AU, et al. Identifying a cut-off point for normal mobility: a comparison of the timed "up and go" test in community-dwelling and institutionalised elderly women. Age Ageing. 2003;32:315-320

78. Shumway-Cook A, Brauer S, Woollacott M. Predicting the probability for falls in community-dwelling older adults using the Timed Up \& Go Test. Phys Ther. 2000;80:896-903.
79. Siegel AB, Lachs M, Coleman M, Leonard JP. Lymphoma in elderly patients: novel functional assessment techniques provide better discrimination among patients than traditional performance status measures. Clin Lymphoma Myeloma. 2006;7:65-69.

80. Green P, Woglom AE, Genereux P, et al. Gait speed and dependence in activities of daily living in older adults with severe aortic stenosis. Clin Cardiol. 2012;35:307-314.

81. Peters DM, Fritz SL, Krotish DE. Assessing the reliability and validity of a shorter walk test compared with the 10 -meter walk test for measurements of gait speed in healthy, older adults. J Geriatr Phys Ther. 2013;36:24-30.

82. Kon SS, Patel MS, Canavan JL, et al. Reliability and validity of 4-metre gait speed in COPD. Eur Respir J. 2013;42:333-340.

83. Jones CJ, Rikli RE, Beam WC. A 30-s chair-stand test as a measure of lower body strength in community-residing older adults. Res Q Exerc Sport. 1999;70:113-119.

84. de Boer JB, Sprangers MAG, Aaronson NK, Lange JMA, Van Dam FS. The feasibility, reliability and validity of the EORTC QLQ-C30 in assessing the quality of life of patients with a symptomatic HIV infection or AIDS (CVC IV). Psychol Health. 1994;9:65-77.

85. Osoba D, Zee B, Warr D, Kaizer L, Latreille J. Psychometric properties and responsiveness of the EORTC quality of life questionnaire (QLQ-C30) in patients with breast, ovarian and lung cancer. Qual Life Res. 1994;3:353-364

86. Jacobsen PB, Le-Rademacher J, Jim H, et al. Exercise and stress management training prior to hematopoietic cell transplantation: Blood and Marrow Transplant Clinical Trials Network (BMT CTN) 0902. Biol Blood Marrow Transplant. 2014;20:1530-1536. 